\title{
Alteration of hTERT full-length variant expression level showed different gene expression profiles and genomic copy number changes in breast cancer
}

\author{
SUN Y. RHA ${ }^{1,2}$, HEI C. JEUNG ${ }^{1}$, WOO I. YANG ${ }^{2,3}$, JIN J KIM ${ }^{4}$, \\ TAE J. $\mathrm{OH}^{5}$, SUNG W. AN ${ }^{1,5}$ and HYUN C. $\mathrm{CHUNG}^{1,2}$ \\ ${ }^{1}$ Cancer Metastasis Research Center, ${ }^{2}$ Brain Korea 21 Project for Medical Science, ${ }^{3}$ Department of Pathology, \\ Yonsei University College of Medicine, Seoul 120-752; ${ }^{4}$ Department of Laboratory Medicine, \\ Inha University Hospital, Incheon; ${ }^{5}$ Microarray Division, GenomicTree Inc., Daejon 305-390, Korea
}

Received November 14, 2005; Accepted December 29, 2005

\begin{abstract}
We analyzed hTERT splicing patterns with respect to telomerase activity in breast cancer. Using a cDNA microarray in 22 cell lines, we observed the difference in expression profiling based on the different levels of full-length variant expression with 71 selected genes. Using 33 known genes that act with the telomerase complex, we performed unsupervised clustering with all cell lines, and found a clustering tendency related to the full-length variant expression level. Using arraybased $\mathrm{CGH}$, highly altered genomic copy number changes were found more often in MCF-7 (159 genes) than in MDAMB-231 (109 genes) and MDA-MB-435 (49 genes), suggesting more genomic changes in MCF-7 cells. On comparing MCF-7 with MDA-MB231 and MDA-MB-435 cell lines, we identified 8 genes with different copy numbers, including dystroglycan, which is located in the p12-21.2 area of chromosome 3 . In conclusion, alterations in the level of the full-length variant of hTERT showed different gene expression profiles and genomic copy number changes in breast cancer, which require further study into their cause-and-effect relationship.
\end{abstract}

\section{Introduction}

Telomerase activation is an adaptive response to protect excessive telomere loss in highly proliferative cells. hTERT transcripts are observed in various immortalized cell lines and cancers (1-3). However, the hTERT expression level does not perfectly correlate with telomerase activity (4).

A total of six alternative splicing sites (four insertion sites and two deletion sites) have been identified within hTERT

Correspondence to: Dr Hyun Cheol Chung, Cancer Metastasis Research Center, Yonsei University College of Medicine, Seoul 120-752, Korea

E-mail: unchung8@yumc.yonsei.ac.kr

Key words: alternative splicing, breast cancer, expression profiling, hTERT, microarray-based CGH
mRNA. Although the positions of the spliced sites suggest that many of the variants do not code for functional reverse transcriptase, the exact functions of the alternatively spliced variants of hTERT are unknown. Actually, the $B$ splice variant does not reconstitute active telomerase activity in an in vitro transcription and translation experiment (5). Therefore, it is possible that alternative splicing plays a role in reducing telomerase activity without reducing hTERT transcription. Some cancers express spliced variants of hTERT with no telomerase activity.

There was a highly uniform pattern of splicing in telomerase-positive cancer cells. Approximately 5\% of total hTERT mRNA is full-length, $80-90 \%$ is $B$-spliced, $5-15 \%$ is $\alpha / \beta$-spliced, and $<1 \%$ is $\alpha$-spliced (6). This pattern indicates that a common splicing mechanism among different cell types determines the splicing pattern of mRNA. A weak correlation was found between the full-length variant level and telomerase activity in cancer cells (6) and the endometrium and myometrium (7). In neuroblastoma, proliferative activity showed a tendency toward an association with telomerase activity, hTERT mRNA, and the full-length variant (8).

The aim of our study was to analyze the gene expression pattern based on hTERT splicing, especially the full-length variant expression in breast cancer.

\section{Materials and methods}

Cell lines and tissue. Eighteen cell lines, including 293 control cell lines, were obtained directly from the American Type Culture Collection (Rockville, MD). Additionally, four human cancer cell lines established at the Cancer Metastasis Research Center, Yonsei University College of Medicine, Seoul, Korea, including three gastric cancer cell lines acquired from ascitic fluid of gastric cancer patients, were used. Cells were incubated in Eagle's minimum essential media (EMEM; JRH Bioscience, USA) at $37^{\circ} \mathrm{C}$ in a $5 \% \mathrm{CO}_{2}$ incubator. The origins of cells are summarized in Table I.

DNA and RNA isolation. DNA was prepared using phenol/ chloroform/isoamyl alcohol from cultured cells and fresh frozen normal placenta tissue. Total RNA was isolated from 
Table I. Expression of telomerase activity and of alternative splicing forms in cancer cell lines.

\begin{tabular}{|c|c|c|c|c|c|c|}
\hline Cell line & Origin & Telomerase activity & Full-length & $\alpha$ variant & $\beta$ variant & $\alpha / \beta$ variant \\
\hline BRN & Glioma & - & - & - & ++ & + \\
\hline SK-LU-1 & Lung & - & - & - & + & - \\
\hline 293 & Kidney & + & +++ & + & +++ & + \\
\hline A549 & Lung & + & ++ & + & +++ & + \\
\hline MDA-MB-231 & Breast & + & +++ & + & +++ & + \\
\hline MCF-7 & Breast & + & ++ & + & +++ & + \\
\hline MDA-MB-435 & Breast & + & +++ & + & +++ & + \\
\hline U87-MG & Glioblastoma & + & ++ & + & +++ & + \\
\hline НСТ-116 & Colon & + & +++ & - & +++ & + \\
\hline DLD-1 & Colon & + & ++ & + & ++ & + \\
\hline Colo205 & Colon & + & +++ & + & +++ & + \\
\hline SK-Mel-2 & Melanoma & + & ++ & + & +++ & + \\
\hline HL-60 & AML & + & +++ & + & +++ & + \\
\hline HТ-1080 & Sarcoma & + & +++ & + & +++ & + \\
\hline HeLa & Cervix & + & +++ & + & +++ & + \\
\hline Capan-2 & Pancreas & + & ++ & + & ++ & + \\
\hline YCC-P-1 & Pancreas & + & +++ & + & +++ & + \\
\hline SK-HEP-1 & Liver & + & +++ & + & +++ & + \\
\hline AGS & Stomach & + & +++ & + & +++ & + \\
\hline YCC-S-2 & Stomach & + & +++ & + & +++ & + \\
\hline YCC-S-3 & Stomach & + & + & - & +++ & - \\
\hline YCC-S-16 & Stomach & + & + & + & +++ & + \\
\hline
\end{tabular}

(-), Negative; (+), positive.

cells and tissues using Trizol reagent (Invitrogen, UK), following the supplier's instructions. Concentrations of DNA and RNA were determined by UV spectrophotometry.

TRAP assay. Each tissue sample was washed in ice-cold washing buffer (10 mM HEPES-KOH pH 7.5, $1.5 \mathrm{mM} \mathrm{MgCl}_{2}$, $10 \mathrm{mM} \mathrm{KCl}$, and $1 \mathrm{mM}$ dithiothreitol) and then homogenized with $100 \mu \mathrm{l}$ of ice-cold lysis buffer [10 mM Tris- $\mathrm{HCl}$ (pH 7.5), $1 \mathrm{mM} \mathrm{MgCl} 2,1 \mathrm{mM}$ EGTA (egtazic acid), $0.1 \mathrm{mM}$ phenylmethylsulfonyl fluoride, $5 \mathrm{mM}$ ß-mercaptoethanol, $0.5 \%$ CHAPS, and $10 \%$ glycerol]. The homogenate was incubated on ice for $30 \mathrm{~min}$ and centrifuged at 15,000 x g for $30 \mathrm{~min}$ at $4^{\circ} \mathrm{C}$. Protein concentrations in each sample were determined using a Bio-Rad protein assay kit (Bio-Rad, Hercules, CA). The TRAP assay was performed as follows: $20 \mu \mathrm{l}$ of each extract was assayed in $50 \mu \mathrm{l}$ of the reaction mixture containing $20 \mathrm{mM}$ Tris- $\mathrm{HCl}(\mathrm{pH} 8.3), 1.5 \mathrm{mM} \mathrm{MgCl}_{2}$, $63 \mathrm{mM} \mathrm{KCl}, 0.005 \%$ Tween-20, $1 \mathrm{mM}$ EGTA, $50 \mu \mathrm{M}$ deoxynucleotide triphosphates, $0.5 \mu 1\left[\alpha_{-}{ }^{32} \mathrm{P}\right] \mathrm{dCTP}(3000 \mathrm{Ci} / \mathrm{mmol}$; Buckinghamshire, UK), $0.1 \mu \mathrm{g}$ of the TS oligonucleotide (5'AATCCGTCGAGCAGAGTT-3'), $1 \mu \mathrm{g}$ of T4 gene 32 protein, bovine serum albumin $(0.1 \mathrm{mg} / \mathrm{ml})$ and 2 units of Taq DNA polymerase in an assay tube containing $0.1 \mu \mathrm{g}$ of $\mathrm{CX}$ primer (5'-CCCTTACCCTTACCCTTACCCTAA-3'), which was sealed with wax at the bottom of the tube (Ampliwax; PerkingElmer Cetus, Foster City, CA). After 30-min incubation at $23^{\circ} \mathrm{C}$, the reaction mixture was amplified for 30 cycles at $94^{\circ} \mathrm{C}$ for $30 \mathrm{sec}, 50^{\circ} \mathrm{C}$ for $30 \mathrm{sec}$ and $72^{\circ} \mathrm{C}$ for $90 \mathrm{sec}$, and then for $10 \mathrm{~min}$ at $72^{\circ} \mathrm{C}$. Analysis of $10 \mu \mathrm{l}$ of each PCR product was performed on $12 \%$ non-denaturing acrylamide gels. To compare the optical densities (ODs) of telomerase activity from each sample with the same baseline, TRAP assays were performed using the same amount $(6 \mu \mathrm{g})$ of tissue extracts (9).

Alternative splicing of hTERT. To evaluate hTERT mRNA splicing, we performed RT-PCR using primer sets for the reverse transcriptase domain of the hTERT transcript (1). Total RNA $(1 \mu \mathrm{g})$ was used to generate cDNA from each sample (Omniscript; Qiagen, Germany). The cDNA samples were amplified in a $5 \mu 1$ reaction mixture containing $0.25 \mu \mathrm{Ci}$ of $\left(\alpha{ }^{32} \mathrm{P}\right) \mathrm{dCTP}$ (Amersham, Arlington Heights, IL) and $0.2 \mu \mathrm{M}$ of each primer. The first hTERT cDNA amplification used TERT-1784S (CGGAAGAGTGTCTGGAGCAA) and TERT-1928A (GGATGAAGCGGAGTCTGGA) oligonucleotides with initial heating at $94^{\circ} \mathrm{C}$ for $90 \mathrm{sec}$, followed by 33 cycles at $95^{\circ} \mathrm{C}$ for $20 \mathrm{sec}, 68^{\circ} \mathrm{C}$ for $40 \mathrm{sec}$, and $72^{\circ} \mathrm{C}$ for 30 sec. Primers 774 (GGGAATTCAAAACTGGAACGG TGAAGG) and 775 (GGAAGCTTATCAAAGTCCTCGGC CACA) were added at $72^{\circ} \mathrm{C}$ during cycle 13 as a $B$-actin internal control. The second hTERT cDNA amplification used TERT-2164S (GCCTGAGCTGTACTTTGTCAA) and TERT-2620A (CGCAAACAGCTTGTTCTCCATGTC) oligonucleotides with initial heating at $94^{\circ} \mathrm{C}$ for $90 \mathrm{sec}$, followed by 35 cycles at $95^{\circ} \mathrm{C}$ for $25 \mathrm{sec}, 68^{\circ} \mathrm{C}$ for $50 \mathrm{sec}$, 


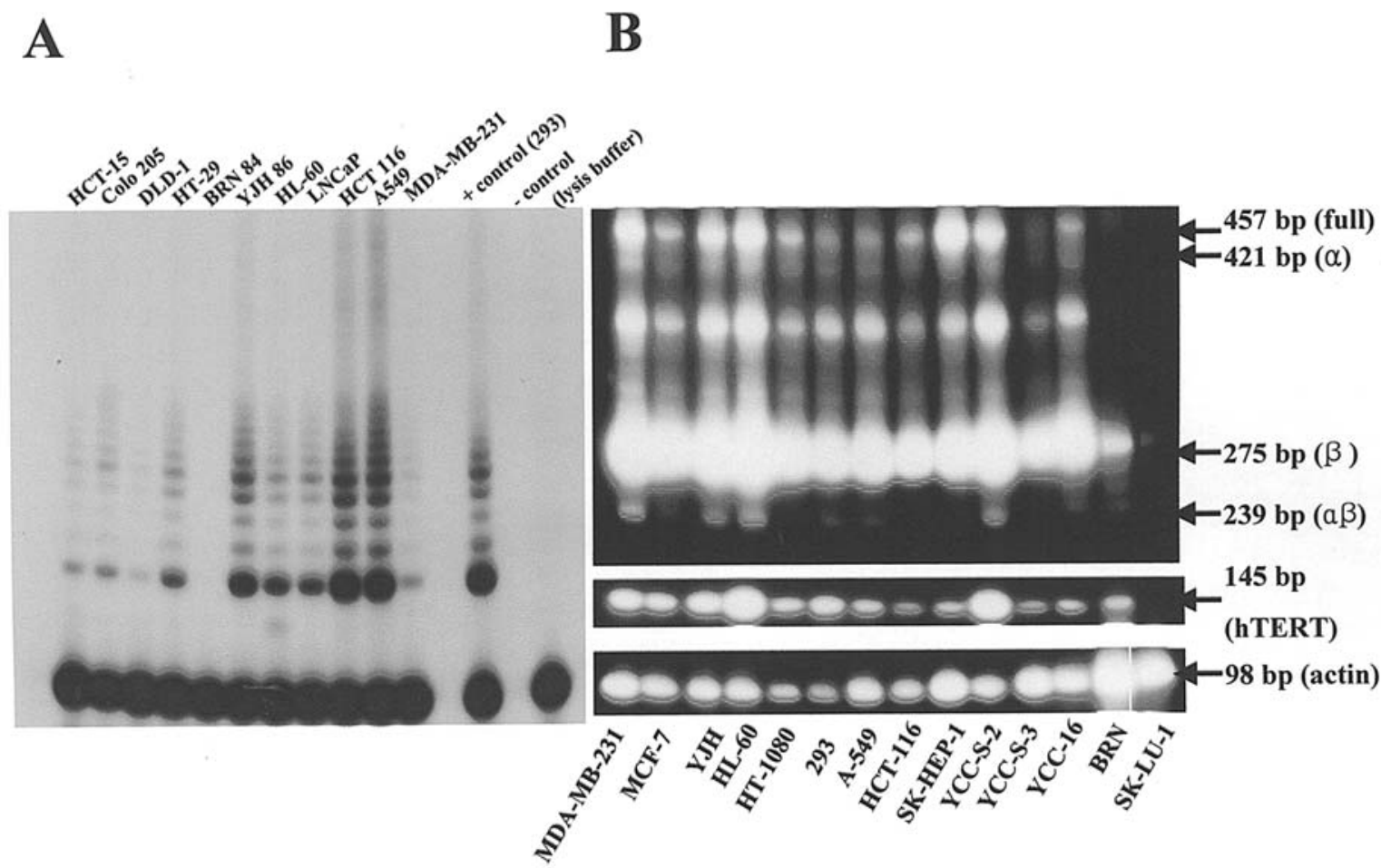

Figure 1. (A) Telomerase activity of each cell line as determined by conventional TRAP assay. (B) Detection of spliced variants of hTERT by RT-PCR in each cell line. (+), 293 cell line as a positive control; (-), negative control by lysis buffer; full, full-length variant; $\alpha, \alpha$ variant; $\beta, \beta$ variant; and $\alpha / \beta, \alpha$ and $\beta$ variant.

and $72^{\circ} \mathrm{C}$ for $50 \mathrm{sec}$. Primers 774 and 775 were added at $72^{\circ} \mathrm{C}$ during cycle 15 as a $B$-actin internal control. Amplified products were electrophoresed in $5 \%$ polyacrylamide-urea gel and visualized using a phosphoimaging scanner (Vilber Lourmat Co., France). Bands from each tissue were compared to the control and expressed in arbitrary units. We graded band densities as + (1-50), ++ (51-100) and +++ (>100).

Gene copy number change and expression profiling analyses by cDNA microarray. Human cDNA microarrays containing 7,500 and 17,000 genes (Genomic Tree Inc. Korea) were used for RNA expression profiling and array-based CGH, respectively. For array-based CGH, $6 \mu \mathrm{g}$ of DpnII-digested genomic DNA was cleaned using a QIAquick PCR purification kit (Qiagen) and fluorescent labeled using a Bioprime labeling kit (Invitrogen, USA). Normal placenta genomic DNA was labeled with $\mathrm{Cy} 3$ as a reference and test DNA was labeled with Cy5. The reaction mixtures were incubated at $37^{\circ} \mathrm{C}$ for $2 \mathrm{~h}$ in the dark, and reactions were stopped by adding $5 \mu \mathrm{l}$ of $0.5 \mathrm{M}$ EDTA, $\mathrm{pH}$ 8.0. For the expression profiling analyses, we used Yonsei reference RNA, which is composed of an RNA pool obtained from 11 cancer cell lines in equal amounts: A549 (lung), AGS (gastric), Caki-2 (kidney), HCT116 (colon), HeLa (cervix), HL60 (acute promyelocyte leukemia), HT1080 (sarcoma), MDA-MB231 (breast), MOLT4 (T-lymphoblast), SK-Hep1 (liver), and U87MG (brain) (CMRC, Yonsei University College of Medicine, Seoul, Korea). Reference RNA (40 $\mu \mathrm{g})$ was labeled with Cy3-dUTP, and $40 \mu \mathrm{g}$ of test RNA was labeled with Cy5-dUTP using Superscript II enzyme (Invitrogen, USA). Hybridization and washing methods were the same for array-based CGH and RNA expression profiling, as detailed below. cDNA microarray was prehybridized in
3.5X SSC, $0.1 \%$ SDS, $10 \mathrm{mg} / \mathrm{ml} \mathrm{BSA}$ for $1 \mathrm{~h}$ at $42^{\circ} \mathrm{C}$ before hybridization with the labeled targets. Cy5- and Cy3-labeled targets were mixed with $30 \mu \mathrm{g}$ human Cot-1 DNA, $20 \mu \mathrm{g}$ poly(dA)-poly(dT), and $100 \mu \mathrm{g}$ yeast tRNA. A Microcon-30 filter (Amicon, MA, USA) was used to purify and concentrate the hybridization mixture, which was then adjusted to $3.4 \mathrm{X}$ SSC and $0.3 \%$ SDS in a final volume of $90 \mu 1$. Following denaturation at $100^{\circ} \mathrm{C}$ for $1.5 \mathrm{~min}$ and $30 \mathrm{~min}$ of pre-annealing at $37^{\circ} \mathrm{C}$, the labeled target was hybridized to the array at $65^{\circ} \mathrm{C}$ for 16-24 $\mathrm{h}$. The slide was then washed for $2 \mathrm{~min}$ each in $0.5 \mathrm{X}$ SSC $/ 0.01 \%$ SDS, $0.06 \mathrm{X}$ SSC/0.01\% SDS and 0.05X SSC at room temperature and spun-dried before scanning. Hybridized arrays were scanned using a GenePix 4000B (Axon Instruments, USA)

\section{Statistical analysis of $C G H$ and cDNA microarray data}

Filtering method. Fluorescence signals were determined after subtracting the background intensity from the spot intensity using a GenePix Pro 4.0 (Axon Instruments, USA). Poor signals $[(\mathrm{F} 532 \mathrm{~nm}-\mathrm{B} 532 \mathrm{~nm})+(\mathrm{F} 635 \mathrm{~nm}-\mathrm{B} 635 \mathrm{~nm})<500)$ were removed for further analysis. We used $\log (\mathrm{R} / \mathrm{G})$ to evaluate relative intensity, where $\mathrm{R}$ and $\mathrm{G}$ represented the Cy5 and $\mathrm{Cy} 3$ fluorescent intensities, respectively. Spots missing in $>20 \%$ of the arrays tested were filtered out. The remaining missing values were adjusted using the $\mathrm{k}$ nearest neighbor (k-NN) method. To correct differences originating from intersample labeling efficiencies, the 'intensity-dependent withinpin-tip normalization with Lowess method' was used (10).

Gene selection methods. In array-based CGH, we applied the significance analysis of microarray (SAM) assay system (11). Compared to normal placenta genomic DNA, we defined a 
Table II. Functional annotation of 71 genes selected by supervised clustering of the cell lines based on the level of full-length variant expression.

\begin{tabular}{lc}
\hline Functional category & Percent (number of genes) \\
\hline Intracellular signaling cascade & $9.9 \%(7)$ \\
Protein modification & $9.9 \%(7)$ \\
Macromolecule biosynthesis & $7.0 \%(5)$ \\
Protein biosynthesis & $7.0 \%(5)$ \\
Transcription & $7.0 \%(5)$ \\
Adenyl nucleotide binding & $5.6 \%(4)$ \\
Cell cycle & $5.6 \%(4)$ \\
Cell surface receptor linked signal transduction & $5.6 \%(4)$ \\
Cytoskeleton & $5.6 \%(4)$ \\
Integral to plasma membrane & $5.6 \%(4)$ \\
Intracellular transport & $5.6 \%(4)$ \\
Protein transport & $5.6 \%(4)$ \\
Defense response & $4.2 \%(3)$ \\
Guanyl nucleotide binding & $4.2 \%(3)$ \\
Hydrolase activity, acting on acid anhydrides, in phosphorus-containing anhydrides & $4.2 \%(3)$ \\
Phosphate metabolism & $4.2 \%(3)$ \\
Phosphotransferase activity, alcohol group as acceptor & $4.2 \%(3)$ \\
Transcription cofactor activity & $4.2 \%(3)$ \\
Unclassified & $52.1 \%(37)$ \\
\hline
\end{tabular}

gene alteration in each cell line as a copy number change of $>0.5$, and 'highly altered genes' as genes with a copy number change of $>1.0$. In expression profiling, we used the t-test and selected genes with a p-value of 0.01 .

Clustering and gene mapping. For information on gene locations regarding the chromosome and ontology, we used GeneSpring software (Silicon Genetics, USA). Using the ontology information, we categorized genes based on genomescale datasets (12) and performed hierarchical clustering based on the Pearson correlation equation (Silicon Genetics).

\section{Results}

Comparison of variant expression. BRN and SK-LU-1 cells expressed neither telomerase activity nor the full-length variant, but expressed either the $\alpha / \beta$ variant or $\beta$ variant. With the exception of HCT-116 and YCC-S-3 cells, all other cells expressed telomerase activity and the four types of variants (Table I and Fig. 1).

Comparison of gene expression patterns based on full-length variant expression. As 5 cell lines (A549, MCF-7, U87-MG, SK-Mel-2, and Capan-2) expressed all of the splicing forms and a relatively lower level of full-length variant than the other cell lines, we compared the gene expression patterns of these cell lines with those of the 10 cell lines with a higher level of full-length variant expression. We were able to select 71 genes that were expressed differently in these 5 cells (Fig. 2A and Table II). We found that the YCC-S-3 cell line, which expresses a lower level of full-length variant without any $\alpha$ and $\alpha / \beta$ variant expression, was clustered to those
5 cell lines with a relatively low level of full-length variant. As a technical control, we used a tumor mass xenografted into nude mice with the HCT-116 cell line (HCT-116M). This mass was clustered with the parent HCT-116 cell line (Fig. 2A). When we used 33 genes known as telomeraserelated genes for the unsupervised clustering of the cell lines, the cell lines showing a higher level of expression of the fulllength variant were found to show a tendency to cluster (Fig. 2B).

Comparison of copy number changes based on full-length variant expression. Among breast cancer cell lines, MCF-7 cells expressed a relatively different level of full-length variant compared to MDA-MB-231 and MDA-MB-435, so we compared the genomic changes in these three cell lines. When we focused on gene copy number changes, 'highly altered genes' were found more often in MCF-7 (159 genes) than in MDA-MB-231 (109 genes) and MDA-MB-435 (49 genes) cells, suggesting more genomic copy number changes in MCF-7 cells. We also found 8 genes, located in the p12-21.2 area of chromosome 3 , which showed differences in gene copy number in MCF-7 versus MDA-MB231 or MDA-MB435 (Fig. 3). Four different copy number change patterns were observed in these 8 genes. First, myosine light chain polypeptide 3 , a novel neural/endocrine-specific cytosolic and peripheral membrane protein coding gene (CADPS), spinocerebellar ataxia 7 and one EST showed higher copy numbers in MCF-7 cells and no changes in MDA-MB-231 or MBA-MB-435 cells compared to the control placenta gene. Second, MDA-MB-231 and MDA-MB-435 cells showed higher gene copy numbers of CCR5, a gene coding the $\beta$ chemokine receptor family, compared to MCF-7. Third, 


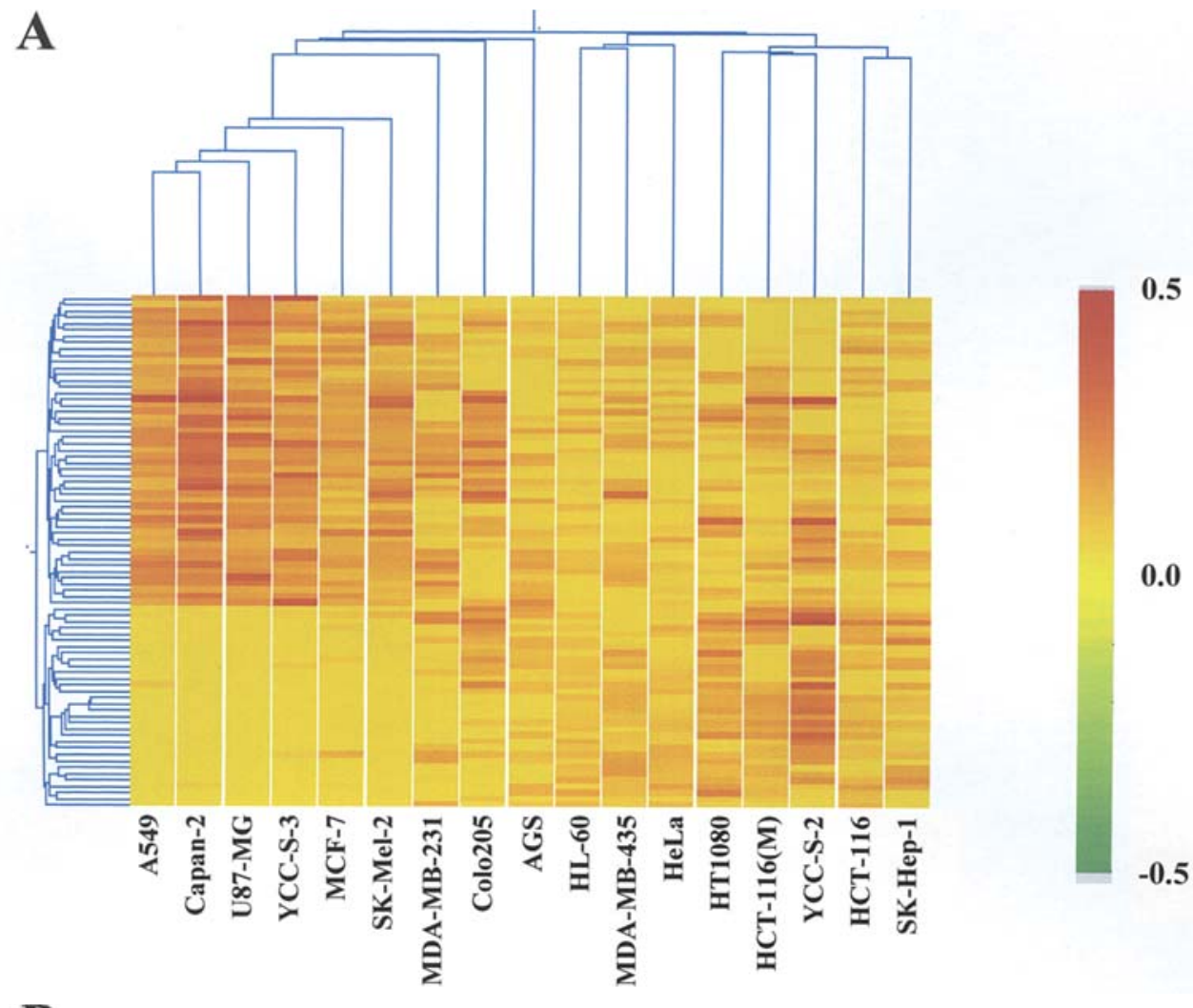

B
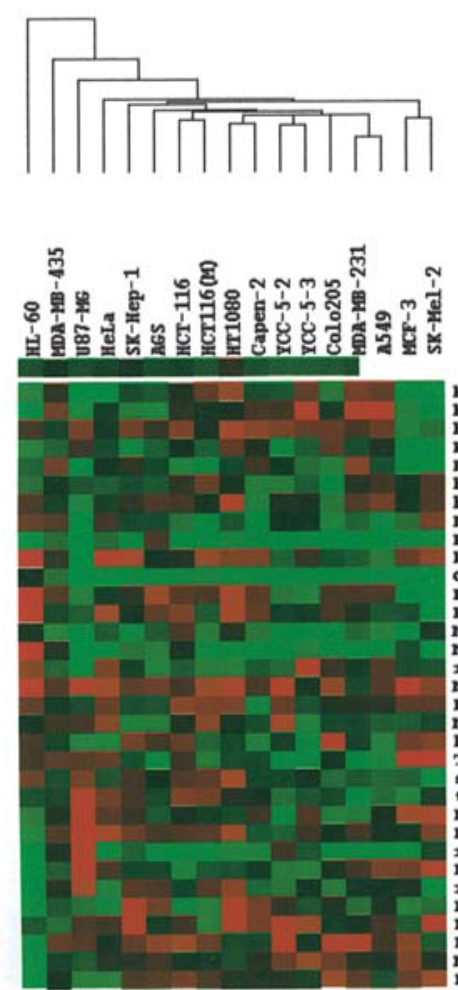

heat shook 7okba protein 1-1ike

heat whook 7okDa protein $1-1$ a

homeodomain interacting protein kiname

Ram-GTPam-activating pxotein binding pxotein 2

DHA topoimomexase II, alpha imo

hTERT hook $90 \mathrm{kD}$ pxotein 1 , beta

DWn topoimomexase II binding protein

RAs guany1 xeleaming pxotein 1 (

CD69 antigen

RAs guanyi releasing protein 2

DMA topoina

MYO proto-oncogene

Max binding pxotein

Din ploymexame mi gma

1yooyte-npeol enhancex

TRF2-intexacting telomexic Rap1 pxotein

mall GTP binding pxotein Rac3

tankyxame

pnas (Holog, enxiched in bxain 2 membex 5

ras homolog gene family, membex

Ras-xelated GTP-binding pxotein

fas homolog gene family, member

pas protein activator like

Dnas (Kmplo) homolog mubfamily B membex 2

max dimexization protein

(Inx dise

Figure 2. Gene expression profiling by cDNA microarray. (A) Supervised clustering and tree-view of cell lines grouped by full-length variant expression level. A total of 71 genes were selected by t-testing at a p-value of $<0.01$. (B) Unsupervised clustering of cell lines using $33 \mathrm{known}$ telomerase-related genes.

MDA-MB231 and MDA-MB-435 cells showed lower copy numbers of the gene encoding inosine monophosphate dehydrogenase activity than MCF-7. Fourth, copy numbers of IL-12A and dystroglycan were reduced in MCF-7 cells but unchanged in MDA-MB-231 and MDA-MB-435 cells.

\section{Discussion}

A total of six alternative splicing sites (four insertion sites and two deletion sites) have been identified and confirmed within hTERT mRNA. In our study, two cell lines without 


\section{Myosin light chain polypeptide 3}

(3p21.3-p21.2)

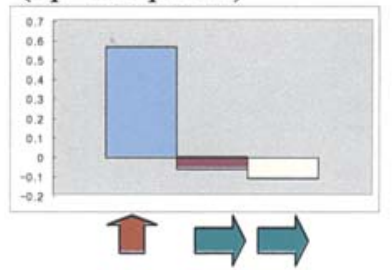

CADPS (3p21.1)

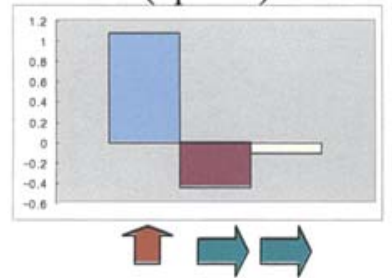

EST (3p21)

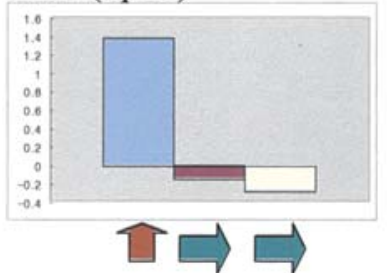

Spinocerebellar ataxia 7 (3p21.1-p12)

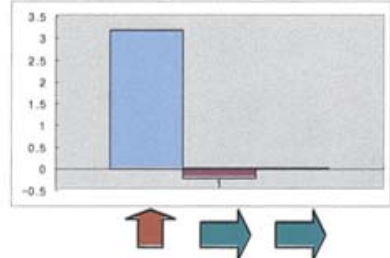

$\operatorname{CCR5}(3 \mathrm{p} 21)$

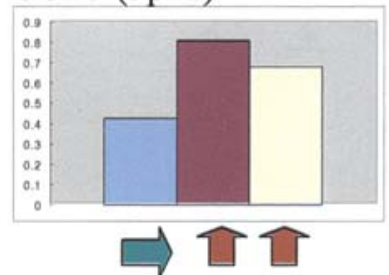

IL-12A (3p12-q13.2)

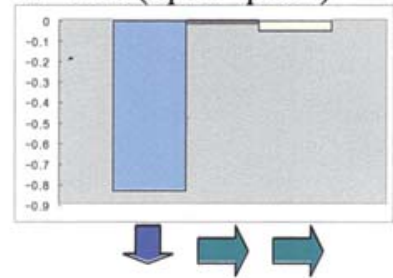

IMP dehydrogenase activity (3p21.2)

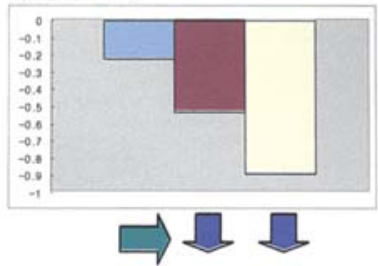

Dystroglycan 1 (3p21)

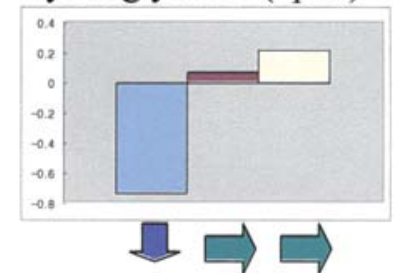

MCF-7

Ð increased

MDA-MB-231 உ decreased

MDA-MB-435 $\Rightarrow$ no change

Figure 3. The copy number change of genes located in the 3p12-21.2 region of chromosome 3, as detected by array-based CGH. Eight genes that showed differential copy number patterns in MCF-7 versus MDA-MB-231 or MDA-MB-435 cell lines were selected.

telomerase activity did not express the full-length form, whereas they did express $\alpha$ or $\beta$ variants. This mechanism would explain the discordant finding of an hTERT transcript without detectable telomerase activity in neuroblastoma (8).

After the transformation of a normal fibroblast with ectopic expression of hTERT, Lindvall et al found 172 dysregulated genes including epiregulin, which showed correlations with hTERT expression (13). To evaluate the different gene profiling patterns based on the level of full-length variant expression, we performed supervised clustering upon 5 cell lines showing a lower amount of full-length variant than the remaining cells, and selected 71 genes that differentiated between the two cell linage groups with different full-length variant expression. As there were no cell lines that express telomerase activity without full-length variant expression, we did a relative comparison with cells that showed a difference in the full-length variant expression level. Pre-mRNA processing factor 4 (PRP-4), which acts on mRNA splicing, was among the 71 genes. Only half of the selected genes were functionally categorized by the DAVID system (12). Using 33 known genes that act with the telomerase complex (14), we performed unsupervised clustering with all cell lines, and found a clustering tendency related to the full-length variant expression level. Thus, we could suggest that gene expression patterns are different according to the differential expression of the full-length type.

As the full-length variant is considered a marker of telomerase activity, and we had observed the difference in expression profiling based on the different level of full-length variant expression, we hypothesized that different levels of full-length variant expression might represent different genomic copy number changes. To study this assumption, we performed microarray $\mathrm{CGH}$ with the same chips used for expression profiling to compare the gene copy number change on a gene-to-gene level. Pursuing this assumption, we found that genes with a highly altered copy number were more common in the MCF-7 cell line, which was found to have relatively less full-length variant than the MDA-MB-231 and MDA-MB-435 cell lines. We then focused on genes in the chromosome 3p12-21.3 region, which contains a repressor of hTERT (15), and measured copy number changes using the array-based $\mathrm{CGH}$ technique. We found 8 genes whose copy numbers differed in MCF-7 from those in MDA-MB231 and MDA-MB-435 cells. We found that dystroglycan copy numbers were low in the MCF-7 cell line. Dystroglycan is an adhesion molecule responsible for interaction between the extracellular matrix and cytoplasmic compartment. Moreover, loss of dystroglycan has been reported to correlate with a higher tumor stage and metastasis in breast cancer (16). The copy number of CCR5 RANTES, a known proinflammatory cytokine that may facilitate breast cancer metastasis and progression (17), showed no change in MCF-7, while MDAMB-231 and MDA-MB-435 showed an increased copy number. In MCF-7, there were increased copy numbers of myosin light chain polypeptide 3 , in which genetic changes induce hypertrophism of cardiomyocyte; ataxin-7, a potential transcription factor; and CADPS, which is essential for the synthesis of phosphatidylinositol 4,5 bisphosphate (18). Thus, in breast cancer, we could postulate that genomic changes, i.e. loss of the dystroglycan gene, due to deranged telomerase 
activity induced by loss of the full-length variant, may be responsible for phenotypic changes. Mutation or loss of dystroglycan has previously been associated with increased metastatic potential or migration capacity in breast cancer (16). To address this issue directly, we plan to introduce fulllength hTERT cDNA into MCF-7 cells, or alternatively spliced cDNA into MDA-MB-231 and MDA-MB-435 cells to see whether the gene expression profile or genomic copy number changes can be induced.

Alterations in the level of full-length variant of hTERT showed different gene expression profiles and genomic copy number changes in breast cancer, which require further study into their cause-and-effect relationship.

\section{Acknowledgements}

This work was supported by the Korea Science and Engineering Fund through the Cancer Metastasis Research Center at Yonsei University.

\section{References}

1. Ulaner GA, Hu JF, Vu TH, Giudice LC and Hoffman AR: Telomerase activity in human development is regulated by human telomerase reverse transcriptase (hTERT) transcription and by alternate splicing of hTERT transcripts. Cancer Res 58: 4168-4172, 1998

2. Ulaner GA, Hu JF, Vu TH, Giudice LC and Hoffman AR: Tissue-specific alternate splicing of human telomerase reverse transcriptase (hTERT) influences telomere lengths during human development. Int J Cancer 91: 644-649, 2001.

3. Killian A, Bowtell DDL, Abud HE, Hime GR, Venter DJ, Keese PK, Duncan EL, Reddel RR and Jefferson RA: Isolation of a candidate human telomerase catalytic subunit gene, which reveals complex splicing patterns in different cell types. Hum Mol Genet 6: 2011-2019, 1997.

4. Brenner CA, Wolny YM, Adler RR and Cohen J: Alternative splicing of the telomerase catalytic subunit in human oocytes and embryos. Mol Human Reprod 5: 845-850, 1999.

5. Weinrich SL, Pruzan R, Ma L, Ouellette M, Tesmer VM, Holt SE, Bodnar AG, Lichtsteiner S, Kim NW, Trager JB, Taylor RD, Carlos R, Andrews WH, Wright WE, Shay JW, Harley CB and Morin GB: Reconstitution of human telomerase with the template RNA component hTR and the catalytic protein subunit hTRT. Nat Genet 17: 498-502, 1997.

6. Yi X, Shay JW and Wright WE: Quantitation of telomerase components and hTERT mRNA splicing patterns in immortal human cells. Nucleic Acid Res 29: 4818-4825, 2001.
7. Yokoyama Y, Wan X, Takahashi Y, Shinohara A and Tamaya T: Alternatively spliced variant deleting exon 7 and 8 of the human telomerase reverse transcriptase gene is dominantly expressed in the uterus. Mol Human Reprod 7: 853-857, 2001.

8. Krams M, Claviez A, Heidorn K, Krupp G, Parwaresch R, Harms D and Rudolph P: Regulation of telomerase activity by alternate splicing of human telomerase reverse transcriptase mRNA in a subset of neuroblastomas. Am J Pathol 159: 1925-1932, 2001.

9. Wright WE, Shay JW and Piatyazek MA: Modifications of a telomeric repeat amplification protocol (TRAP) result in increased reliability, linearity and sensitivity. Nucleic Acid Res 23: 3794-3795, 1995.

10. Yang YH, Dudoit S, Luu P, Lin DM, Peng V, Ngaai J and Speed TP: Normalization for cDNA microarray data: a robust composite method addressing single and multiple slide systematic variation. Nucleic Acids Res 15, 30: e15, 2002.

11. Dudoit S, Yang YH, Callow MJ and Speed TP: Statistical methods for identifying differentially expressed genes in replicated cDNA microarray experiments. Technical Report, Statistics Department. University of Cambridge, Berkeley, 2000.

12. Dennis G Jr, Sherman BT, Hosack DA, Yang J, Gao W, Lane HC and Lempickie RA: DAVID: database for annotation, visualization, and integrated discovery. Genome Biol 4: R60.1-R60.11, 2003.

13. Lindvall C, Hou Mi, Komurasaki T, Zheng C, Henriksson M, Sedivy JM, Bjorkholm M, Nordenskjold M and Xu D: Molecular characterization of human telomerase reverse transcriptase-immortalized human fibroblasts by gene expression profiling: activation of the epiregulin gene. Cancer Res 63: 1743-1747, 2003.

14. Gunes C, Lichtsteiner S, Vasserot AP and Englert C: Expression of the hTERT gene is regulated at the level of transcriptional initiation and repressed by Mad1. Cancer Res 60: 2116-2121, 2000.

15. Szutorisz H, Lingner J, Cuthbert AP, Trott DA, Newbold RF and Nabholz MA: Chromosome 3-encoded repressor of the human telomerase reverse transcriptase (hTERT) gene controls the state of hTERT chromatin. Cancer Res 63: 689-695, 2003.

16. Sgambato A, Migaldi M, Montanari M, Camerini A, Brancaccio A, Rossi G, Cangiano R, Losasso C, Capelli G, Trentini GP and Cittadini A: Dystroglycan expression is frequently reduced in human breast and colon cancers and is associated with tumor progression. Am J Pathol 162: 849-860, 2003.

17. Azenshtein E, Luboshits G, Shina S, Neumark E, Shahbazian M, Weil M, Wigler N, Keydar I and Ben-Baruch A: The CC chemokine RANTES in breast carcinoma progression: regulation of expression and potential mechanisms of promalignant activity. Cancer Res 62: 1093-1102, 2002.

18. Koreh K and Monaco ME: The relationship of hormone-sensitive and hormone-insensitive phosphatidylinositol to phosphatidylinositol 4,5-bisphosphate in the WRK-1 cell. J Biol Chem 261: 88-91, 1986. 